\title{
Palestras de Divulgação Científica de Química: Contribuições para a Crença na Autoeficácia de Estudantes do Ensino Médio
}

\section{Chemistry's Scientific Popularization's Lectures: Contributions to the Self-Efficacy Beliefs of High School Students}

\section{Kenia Naara Parra Ana Cláudia Kasseboehmer \\ Brasil \\ Brasil}

No campo da psicologia educacional, muitos estudos têm diagnosticado constructos como a autoeficácia de estudantes, mas poucos propõem intervenções e avaliam seu potencial para a mudança da autoeficácia. Este estudo avaliou o potencial de palestras de química para a promoção da crença na autoeficácia através de atividades de divulgação científica aplicadas para estudantes do primeiro ano do Ensino Médio de três escolas públicas ao longo de um ano. O estudo é de natureza qualitativa, pautado em entrevistas semiestruturadas com estudantes e professores e seguido da categorização e análise dos resultados. Dentre os fatores que forneceram indícios de fortalecimento das crenças de autoeficácia, destacam-se o aumento do interesse pela química, melhor compreensão dos conceitos químicos e melhor compreensão da natureza da química, bem como do aumento do esforço aplicado para o aprendizado. Tais resultados foram corroborados pelas observações dos professores, à medida que aprofundaram o olhar para suas turmas e notaram particular aumento do esforço e interesse, embora não tenham observado mudanças em toda a sala de aula. Dentre os aspectos das palestras que contribuíram para os resultados, destacam-se a promoção de interação entre os estudantes, engajamento e envolvimento cognitivo a partir das dinâmicas das apresentações, temas das pesquisas científicas, espaços não formais utilizados e formação dos apresentadores. Entretanto, aspectos relacionados à avaliação escolar e falta de diálogo entre professores e estudantes são fatores limitantes dessas atividades para o diagnóstico, intervenção e acompanhamento das turmas. Questões relacionadas à importância de estudos longitudinais para avaliação da crença na autoeficácia também foram apontadas.

Palavras-chave: autoeficácia; divulgação científica; química.

In the educational psychology field, many studies have been doing the diagnoses of constructs such as student self-efficacy, but few studies propose interventions and assess the potential for self-efficacy change over time. This study evaluated the potential of Chemistry's lectures to promote the self-efficacy beliefs through scientific popularization 
activities applied to students of the first year of high school in three public schools during a year. The study has a qualitative nature, based on semi-structured interviews with students and teachers and followed by the categorization and analysis of the results. Among the factors that provided evidence for the strengthening of self-efficacy beliefs, we highlight the interest in Chemistry, a better understanding of Chemistry concepts and a better understanding about the nature of Chemistry, as well as an increase in the effort applied to learning. These results were corroborated by the observations of the teachers as they paid more attention to their classroom and noticed a particular increase in effort and interest, although they did not observe changes in all students. Among the aspects of the lectures that contributed to the results, we highlight the promotion of students' interaction, engagement and cognitive involvement based on the dynamics of presentations, research topics, non-formal spaces used and presenters training. However, aspects related to school evaluation and lack of dialogue between teachers and students are limiting factors for the diagnosis, intervention and monitoring of the classes. Issues related to the importance of longitudinal studies for self-efficacy beliefs evaluation were also pointed out.

Keywords: self-efficacy; science popularization; chemistry.

\section{Introdução}

\section{Teoria Sócio Cognitiva}

De acordo com a Teoria Sócio Cognitiva, fatores pessoais são compostos por eventos biológicos, afetivos e cognitivos e se relacionam a fatores comportamentais e ambientais. Forma-se uma espécie de tríade de causa recíproca em que cada um influencia e é influenciado pelos demais num processo bilateral (Bandura, 2009).

Dentro dos limites biológicos, a natureza humana tem potencialidade vasta e pode ser modelada em uma variedade de formas por experiências diretas e observáveis. Essa plasticidade ou capacidade de adaptação é intrínseca e resultado da evolução do ser humano. Dentre as capacidades claramente humanas tem-se a comunicação simbólica, premeditação, autorregulação avaliativa e autoconsciência reflexiva (Bandura, 2009).

Através da premeditação, as pessoas se motivam e conduzem suas ações em antecipação aos eventos futuros. A ligação entre a premeditação e a ação de fato ocorre através dos processos autorregulatórios, ou seja, pela capacidade de dar forma a cursos apropriados de ação, motivar e, também, regular a execução para que eles não fiquem restritos apenas ao campo do planejamento. Uma vez executada a ação, a capacidade humana de autoanálise e autorreflexão provoca, então, o julgamento das ações perante as premeditações, resultados obtidos, crença e ações de outras pessoas e, assim, optam por adequar ou não seus pensamentos e ações (Bandura, 2001). Nesse processo, a vulnerabilidade à tensão, estresse, depressão ou resiliência às adversidades está intimamente relacionada à crença na autoeficácia (Bandura, 1994). 
Para Bandura (2009), nenhuma crença autorreferencial é mais determinante para a ação humana do que a crença na autoeficácia, uma vez que a convicção no sucesso ou nos efeitos desejados em detrimento dos indesejados é o que incentiva a ação.

A autoeficácia influencia pensamentos e fatores como ânimo ou desânimo, otimismo ou pessimismo, esforço despendido para realização de algo, tempo de persistência frente a obstáculos, resiliência perante adversidades, tensão ao lidar com exigências ambientais e percepção sobre as próprias ações (Bandura, 2009).

Sendo a autoeficácia determinante para o envolvimento, execução de atividades e comportamento humano, estudos sobre esse constructo têm ganhado relevância no cenário nacional e internacional (Iaochite, Costa Filho, Matos, \& Sachimbombo, 2016).

Bandura (2009) usou a Teoria Sócio Cognitiva para examinar os mecanismos psicológicos da comunicação em massa que afetam o pensamento e ação humana. $\mathrm{O}$ autor discutiu o quanto a modelagem influencia a adoção de novas práticas sociais e padrões de comportamento de diferentes maneiras, além de instruir as pessoas sobre novas formas de pensar e se comportar por meio de demonstração ou descrição informativa. Entre outras consequências, a modelagem de informações eficiente não só cultiva competências, mas também melhora a sensação de autoeficácia necessária para transformar conhecimento e habilidades em cursos de ação bem sucedidos.

Já Mencl, Tay, Schwoerer e Drasgow (2012), ao examinarem mudanças na percepção de autoeficácia de vendedores ao longo do tempo, mostraram que a autoeficácia para uma atividade específica aumenta após a participação em programas de treinamento bem sucedidos e isso leva ao aumento da autoeficácia geral, situação na qual os vendedores sentem-se mais confiantes e motivados para outras tarefas e situações.

Estudos nas áreas da saúde e desenvolvimento organizacional vêm aplicando estratégias de treinamento e ensino para a promoção da autoeficácia e verificam que fatores como o contexto e as dinâmicas utilizadas influenciam a percepção do estudante sobre a própria capacidade de aprender. No entanto, a literatura carece de estudos que avaliem o ambiente de aprendizagem e em especial, as atividades educativas para a promoção da autoeficácia para o aprendizado no Ensino Básico.

No contexto educacional, a maior parte dos estudos avalia a autoeficácia de estudantes com o objetivo de diagnosticá-la ou mensurá-la e assim, estabelecer relações com a motivação para a realização de atividades educacionais, autorregulação para o aprendizado e o desempenho acadêmico (Bryan, Glynn, \& Kittleson, 2011; Iaochite et al., 2016). Outros estudos avaliam também a autoeficácia de professores e fatores como o contexto escolar (Friedman, \& Kass, 2001; Goya, Bzuneck, \& Guimarães, 2008; Skaalvik, \& Skaalvik, 2010)

Iaochite et al. (2016) observaram que os estudos brasileiros têm acompanhado o perfil internacional ao privilegiarem aspectos quantitativos, a utilização e validação de escalas e análises da autoeficácia de estudantes do Ensino Básico e Superior. Além disso, são analisadas a autoeficácia docente e sua relação com a satisfação pessoal, profissional, 
motivação para ensinar e motivação dos estudantes.

Dentre os fatores que podem influenciar o esforço, interesse e autoeficácia do estudante, destaca-se a atuação do professor. A crença e prática docente e as consequências para a qualidade do ensino e aprendizado tem sido objeto de estudo em muitas pesquisas. Em fase de transição escolar, por exemplo, o empenho e engajamento do estudante na nova escola tem correlação com o estilo de ensino do professor quando este tem alta crença na autoeficácia pessoal (Midgley, Feldlaufer, \& Eccles, 1989) e se este for orientado para o aprendizado e domínio do conteúdo ao contrário da orientação para a performance do estudante (Madjar, \& Chohat, 2016).

Para o caso da autoeficácia do professor, Midgley et al. (1989) mostraram que, na matemática, existe uma relação causal entre as opiniões dos estudantes sobre o próprio desempenho, potencial e dificuldade com a matéria e as crenças dos professores sobre sua eficácia pessoal.

Considerando a maleabilidade e suscetibilidade a influências diversas, tem-se que a autoeficácia pode ser promovida através de atividades que, além de transpor o indivíduo para outro ambiente e convívio, envolvam estratégias diversificadas de ensino e estimulação cognitiva (Mencl et al., 2012). Em cursos de enfermagem, estratégias de ensino baseadas em simulações têm mostrado que o pensamento crítico, a motivação para a aprendizagem e habilidades especificas aumentam a crença na autoeficácia (Park, Park, Kim, \& Song, 2016).

Para o caso da química, por exemplo, a promoção da crença na autoeficácia para aprendizagem, entre outros domínios afetivos, tem papel fundamental para aumentar o empenho e comprometimento dos estudantes e o sucesso escolar. Entretanto, fatores como a complexidade dos conceitos, necessidade de abstração e ensino teórico e prático desconexos, têm contribuído para causar desinteresse em estudantes que veem a química como difícil e distante da realidade (Salta, \& Tzougraki, 2004; Cheung, 2009).

No ensino superior, por outro lado, Ferrel e Barbera (2015) relacionaram a autoeficácia de estudantes na disciplina de Química Geral aos diferentes tipos de cursos mostrando que as escalas de avaliação psicométrica podem ser importantes para o diagnóstico da autoeficácia em diferentes momentos e contextos educacionais, especialmente quando o professor quer avaliar o impacto de inovações no ensino.

Desse modo, iniciativas baseadas em intervenções e estratégias de ensino que promovam o ativismo e interação do estudante com diferentes contextos que permeiam a química podem ser desenvolvidas e estudadas a partir da promoção da autoeficácia.

\section{Divulgação Científica: museus, universidades públicas e palestras de divulgação científica da química}

Sob a perspectiva sociocultural, a divulgação científica é entendida como promotora da capacidade crítico-reflexiva do indivíduo na medida em que alia o aprendizado técnico-científico à formação cultural e política. A divulgação científica contribui para que o indivíduo aprenda ciência e se posicione perante questões tanto 
científicas quanto ambientais, de saúde, econômicas e políticas (Kasseboehmer, \& Parra, 2015).

Segundo Kasseboehmer e Parra (2015), a divulgação científica pode ser promovida por diferentes profissionais, além de ser veiculada em diversos formatos e espaços. Nesse aspecto, os espaços de educação não formal, como museus e centros de ciências, têm se destacado pela relação que buscam estabelecer com o desenvolvimento da ciência, seja pelo intuito de conservar, ensinar, treinar tecnicamente ou promover a interação entre a população e cientistas.

Ao longo do tempo pode-se observar a transgressão da imagem do museu de um espaço relacionado à manutenção e divulgação de memórias para um espaço de interdisciplinaridade, ciência e cultura, onde visitantes podem participar de um permanente diálogo com profissionais de várias áreas em um processo que ocorre para além do espaço escolar (Martins, Navas, Contier, \& Souza, 2013; Valente, Cazelli, \& Alves, 2005).

Para Valente et al. (2005), são inúmeras as buscas por transformações dos métodos tradicionais de comunicação empregados nesses espaços para outros que possibilitem o intercâmbio de ideais entre as partes envolvidas.

Em resumo, as formas de comunicação nos museus têm evoluído e passaram de um modelo simplificado - baseado na idéia emissor-receptor, de envio de uma mensagem linear a uma pessoa - para um modelo mais complexo constituído por elementos como a intenção por parte do emissor, o conteúdo da mensagem, a linguagem utilizada, as condições do visitante, os recursos audiovisuais e, principalmente, a possibilidade de estabelecer relações em um sentido até então não previsto: as do visitante com o museu (Valente et al., 2005, p. 198).

De acordo com Falcão (2009, p.16) diversas atividades educacionais podem ser desenvolvidas em museus:

Podem ser entendidas como práticas educativas atividades tais como: visitas "orientadas", "guiadas", "monitoradas" ou mesmo "dramatizadas", programas de atendimento e preparo dos professores, oficinas, cursos e conferências, mostras de filme, vídeos, práticas de leitura, contação de histórias, exposições itinerantes, além de projetos específicos desenvolvidos para comemorar determinadas datas e servir de suporte para algumas exposições. Além dos materiais educativos e informativos editados com a finalidade de servir a estas práticas, tais como: edição de livros, jogos, guias, folders e folhetos diversos, folhas de atividades, kits de materiais pedagógicos, áudio-guide (guia auditivo), aplicativos multimídia, CD-ROM, site institucional na internet, etc.

Para o caso específico de museus de ciência, observa-se a incorporação de propostas para minimizar o analfabetismo científico e tecnológico, dando assim, enfoque aos fenômenos e conceitos científicos a partir do uso de atividades interativas (Valente et al., 2005).

Tais atividades envolvem o discurso expositivo, que em museus de ciências deve ser constituído por diversos saberes mediadores da cultura científica e confrontados na 
elaboração de uma exposição através dos processos de transposições (Marandino, 2005). Dentre os saberes, Marandino (2005) destaca os saberes do senso comum, saberes sábio, saber museológico, saber da comunicação e saber da educação.

Sendo o saber sábio relacionado ao conhecimento produzido pela comunidade de pesquisadores, faz-se importante a participação destes no processo de divulgação científica. Para Kasseboehmer e Parra (2015) cabe à comunidade acadêmica, realizar parcerias com órgãos da esfera pública e privada para fortalecer esses espaços de educação não formal, especialmente as atividades de divulgação científica no país. Além disso, acredita-se que, ao abrirem as portas para eventos e atividades para a população e comunidade escolar no sentido de exercer e fortalecer o tripé ensino-pesquisa-extensão, as universidades públicas passam a promover a educação não formal através de um processo e organização intencional desenvolvida em um espaço coletivo.

No Brasil, as universidades públicas contribuem tanto para a formação de recursos humanos, quanto para a economia e o desenvolvimento do campo científicotecnológico do país (Azevedo, 2005). Uma vez que elas são parte de um processo social amplo (Fávero, 2006), devem repensar continuamente sua missão, especialmente no modo como a sociedade percebe e se apropria dessas contribuições.

Parra, Silva e Kasseboehmer (2015) investigaram a percepção dos estudantes e moradores de São Carlos, no interior de São Paulo, sobre universidades públicas. Eles constataram que as percepções e sentimentos que cercam as universidades públicas são de desconhecimento e complexidade. Ficou evidente a necessidade de mudanças de diferentes esferas e sujeitos, inclusive do docente-pesquisador-extencionista a partir do compromisso com a divulgação científica.

Desse modo, em parceria com grupos de pesquisas do Instituto de Química de São Carlos (IQSC) da Universidade de São Paulo, o presente estudo foi iniciado com o desenvolvimento de palestras de divulgação científica com o intuito de destacar a importância das pesquisas científicas da área, e assim, contribuir para a desmistificação da imagem da química e aproximação entre a universidade e a população em geral, especialmente a escolar.

As palestras são compostas por atividades dinâmicas cujo objetivo é a divulgação das pesquisas do IQSC a partir de atividades audiovisuais e experimentais que possibilitem que os alunos se envolvam e encontrem sentido na pesquisa científica divulgada e nos conteúdos químicos discutidos.

A partir de uma problemática cuja abordagem pode ser econômica, ambiental, cultural ou tecnológica, as palestras envolvem uma breve descrição sobre o grupo de pesquisa e seus objetivos, abordando também as condições de trabalho, equipamentos, dificuldades e avanços. Dentre as várias linhas de pesquisas, seleciona-se uma delas e abordam-se alguns resultados que o grupo vem obtendo, sempre destacando a importância da sua pesquisa para o desenvolvimento da ciência, tecnologia e sociedade.

Independentemente da pesquisa e grupo de pesquisa abordado, o principal objetivo é mostrar a importância das pesquisas científicas e sua relação com a sociedade, 
entre outros aspectos, que geralmente não chegam até o conhecimento de estudantes e reforçam visões distorcidas sobre a Ciência e o cientista. As palestras evidenciam o trabalho em conjunto, as parcerias com outros grupos nacionais e internacionais e de outras áreas da Ciência, os desafios que os pesquisadores enfrentam no desenvolvimento de projetos, busca por investimentos e auxílios e o tempo geralmente demandado para a obtenção de resultados que, muitas vezes, motivam novas pesquisas.

Apesar de motivarem as pesquisas científicas, alguns temas, como química e os medicamentos ou química e a contaminação ambiental, causam desconforto e interpretações errôneas na maioria da população, devido à falta de compreensão, pouco contato com o assunto e dificuldade de se posicionar quando necessário (Dietrich, \& Schibeci, 2003). Deste modo, estes assuntos foram privilegiados e por meio de atividades como experimentação, leitura de jornais e revistas, manipulação de objetos, exibição de vídeos e outros recursos, as palestras abrem espaço para que os estudantes questionem e se expressem à medida que são apresentados às pesquisas.

Nesse processo, o discurso é construído com base nos diversos saberes mediadores da cultura científica, em um processo de transposição ou recontextualização (Marandino, 2004). As palestras são frutos do confronto entre os saberes sábio, saberes da educação, saberes do senso comum, entre outros saberes que devem ser considerados e envolvidos na divulgação científica (Marandino, 2005).

Busca-se também desmistificar a Ciência e mostrar que o cientista, ao contrário do que se divulga, não é dotado de superioridade, mas é um profissional que conduz com responsabilidade e zelo seu trabalho. Ao final da palestra, faz-se o convite para que os estudantes ingressem nas universidades, mostrando programas e auxílios disponíveis.

Segundo esses critérios, seis palestras de divulgação científica da química foram elaboradas ao longo de 2014 e 2015, sendo que quatro delas foram apresentadas ao longo de 2016 para 492 estudantes do Ensino Médio em um total de 12 apresentações.

Com as palestras, buscou-se: aproximar a universidade da comunidade, especialmente a escolar; desmistificar a química; mostrar sua importância e aplicação para a solução de problemas reais e relacionar as técnicas das pesquisas científicas aos conteúdos aprendidos na escola. Nesse contexto, a questão de pesquisa desse estudo é: Qual é a contribuição de palestras de divulgação científica na área de química para a crença na autoeficácia de estudantes do primeiro ano do Ensino Médio?

As hipóteses deste trabalho são que a crença na capacidade para o aprendizado da química possa ser mantida ou promovida à medida que o estudante, de modo interativo e engajado, tenha contato com atividades de divulgação científica.

\section{Metodologia}

O presente estudo é de natureza qualitativa pautado em entrevistas semiestruturadas com estudantes e professores, guiadas através de um roteiro elaborado a partir do problema de pesquisa. A pesquisa qualitativa é apropriada quando se deseja focar no processo de mudança. Para ocorrer efetivamente, ela deve levar em consideração 
os indivíduos envolvidos no processo, demandando maior investimento de tempo, e geralmente amostras menores que as da pesquisa quantitativa, uma vez que prioriza a qualidade dos resultados e não a quantidade (Bogdan, \& Biklen, 1994).

\section{Palestras apresentadas}

$\mathrm{Na}$ primeira palestra é discutido o grande consumo de medicamentos e a contaminação do solo e água, seja durante o seu processo de fabricação, na eliminação de urina e fezes de pacientes ou pelo descarte incorreto de medicamentos que passam do prazo de validade. Desse modo, a partir do norfloxacino, antibiótico para tratamento de doenças infecciosas, a contaminação do meio ambiente é problematizada. A pesquisa desenvolvida pelo Grupo de Cromatografia que detecta e analisa substâncias no meio ambiente e possibilita o acompanhamento do quadro de contaminação para posterior tratamento também é abordada de modo interativo. Nesta palestra, o modo correto de descarte de medicamentos e o conceito de substância química e misturas é discutido. Os estudantes são divididos em grupos e realizam o experimento de cromatografia em papel seguindo um procedimento distribuído pelos apresentadores. Na sequência, os estudantes comparam os resultados de acordo com as cores das canetas hidrocor que escolheram trabalhar e discutem suas hipóteses em grupo e com toda a turma. Por fim, os estudantes conhecem métodos avançados de separação de misturas utilizados em laboratório através de vídeos e da manipulação de artefatos.

A segunda palestra é sobre a pesquisa desenvolvida pelo Grupo de Química Medicinal e mostra o tempo, as etapas de desenvolvimento de fármacos e de que forma um químico pode atuar nesse processo. Na palestra, é debatido o alto consumo de medicamentos e hábitos saudáveis de vida. Algumas das substâncias estudadas pelo grupo para o tratamento do câncer de próstata são abordadas e um experimento colorimétrico para discutir como a espectrofotometria é utilizada nos estudos de toxicidade, essenciais nas primeiras etapas do desenvolvimento de fármacos é realizado. Neste experimento, os grupos de estudantes misturam reagentes químicos em diferentes concentrações e, utilizando apenas a visão, entram em consenso sobre a ordenação dos recipientes de acordo com a intensidade da cor da solução final. Em seguida, os grupos comparam a ordem dos recipientes e discutem as dificuldades que encontraram para fazê-la. Por fim, os apresentadores abordam a espectrofotometria utilizada nos laboratórios através de fotos e vídeos, mostrando a necessidade do uso de técnicas sensíveis a diferenças de concentração de substâncias imperceptíveis a olho nu. Ao final, a possibilidade de utilizar a cromatografia, discutida na palestra anterior, no processo de desenvolvimento de fármacos também é relembrada.

A terceira palestra é baseada na pesquisa do Grupo de Processos Eletroquímicos e Ambientais e aborda histórica e ambientalmente a contaminação aquática e terrestre por corantes, fármacos e pesticidas, apresentando aos participantes os processos eletroquímicos como possíveis tratamentos dessas matrizes contaminadas. A importância dos corantes para a vida humana e o quanto eles vêm sendo alvos de pesquisas que visam 
sua degradação são discutidas. A formação dos radicais livres também é abordada e o experimento de degradação do corante Reativo Azul 19, um contaminante ambiental, é realizado. $\mathrm{O}$ experimento consiste na agitação de uma solução que contenha o corante e palha de aço como fonte de ferro e adição em períodos pré-determinados de água oxigenada. Cada grupo de estudantes escolhe uma variação do experimento e compara, com os demais grupos, o tempo para a solução ficar incolor de acordo com o volume de água oxigenada adicionado. Ao longo da palestra e após o experimento, os apresentadores discutem sobre as substâncias produzidas e seus efeitos em determinados compostos orgânicos, como os corantes. Os apresentadores também relacionam a necessidade de utilizar as técnicas discutidas na segunda palestra para a constatação da degradação do corante.

A quarta palestra trata da corrosão e é iniciada com imagens e notícias de jornal de dois acidentes reais que ocorreram devido à corrosão de metais, enfatizando os problemas econômicos e de segurança por trás deste processo. Os estudantes são questionados sobre como superar esses problemas. Em seguida os trabalhos desenvolvidos pelo Grupo de Eletroquímica Interfacial, visando impedir ou diminuir o processo natural da corrosão através da proteção com a polianilina, são apresentados e discutidos. Durante a palestra, os estudantes fazem experimentos comparando a velocidade de corrosão em diferentes meios e amostras de metais protegidas ou não por polianilina. Cada um dos grupos recebe um conjunto de amostras de metais, como pregos galvanizados e não galvanizados, papel alumínio e palha de aço. Então, em uma solução com diferentes concentrações de sulfato de cobre, os estudantes adicionam as amostras e analisam o processo de oxidação do ferro metálico e redução dos íons cobre da solução. Os estudantes avaliam também o efeito do sal de cozinha quando adicionado nos recipientes e comparam os resultados com a peça de aço recoberta que quando mergulhada nas mesmas soluções não sofre o mesmo processo de oxidação.

\section{Participantes}

Os estudantes participantes cursavam o primeiro ano do Ensino Médio de turmas matutinas de três escolas públicas da cidade de São Carlos, interior de São Paulo. Apesar das três escolas possuírem laboratórios de ciências, os estudantes e professores de química alegaram não utilizá-los com frequência.

A Escola A, criada na década de 1950, é uma escola de porte grande e tradicional na cidade, atendendo pelo menos três bairros da sua região. Conversas informais com o coordenador e professor de química revelaram que a escola costuma desenvolver projetos em parceria com as universidades da cidade. Parte dos estudantes necessita trabalhar no contraturno e possui pouca expectativa de prestar vestibular.

A Escola B, também criada na década de 1950, atende estudantes de quatro bairros vizinhos. Possui médio porte e três turmas do primeiro ano. De acordo com informações de professores, estudantes e direção, nessa escola os estudantes possuem a expectativa de prestar vestibular e uma pequena parte deles costuma se envolver em 
projetos no contraturno.

A Escola C foi fundada em 2014. Localizada em uma região periférica, atende estudantes de pelo menos cinco bairros vizinhos. Possui boa infraestrutura e três turmas do primeiro ano. Por a escola ser nova, ainda não possui um perfil educacional sólido ou fácil de ser caracterizado. Entretanto observações da pesquisadora e informações dos professores, coordenação e funcionários mostraram que a equipe escolar esforça-se para trazer novos projetos além de orientar e motivar os estudantes que, de modo geral, são carentes e, por vezes, transferidos para a escola por motivos familiares, de aprendizagem ou de disciplina. Alguns estudantes trabalham e boa parte não demonstra expectativa de ingressar no ensino superior.

\section{Coleta de dados}

As palestras foram avaliadas e aprovadas previamente pela coordenação educadora do Museu da Ciência "Professor Mário Tolentino" na cidade de São Carlos. Em seguida, passaram por um estudo piloto no museu envolvendo 52 estudantes do primeiro ano do Ensino Médio de duas escolas públicas em 2015. Com base em observações, anotações e gravações de vídeos durante o estudo piloto, foi possível adequar fatores como distribuição dos estudantes pelo ambiente, formação de grupos durante a experimentação e ajustes nas questões para a coleta de dados. Os professores de química responsáveis pelas turmas também contribuíram e sugeriram alterações.

Tanto no estudo piloto quanto na coleta de dados, as palestras foram conduzidas por graduandos bolsistas do curso de licenciatura em química após passarem por um período de formação.

No início do primeiro semestre de 2016, todos os estudantes foram informados sobre o objetivo e desenvolvimento da pesquisa ao longo do ano. Também foram avisados sobre a não obrigatoriedade em participar tanto das palestras quanto da coleta de dados e da liberdade para cancelar a participação a qualquer momento.

Os estudantes foram levados a dois espaços não formais da cidade que contribuam para sua imersão no processo de desenvolvimento e aplicação da Ciência e Tecnologia, mais especificamente da química. Os locais são Museu da Ciência "Professor Mário Tolentino" e o saguão da Biblioteca da Prefeitura do Campus USP de São Carlos. Foram apresentadas quatro palestras de 60 minutos de duração cada. Duas ocorreram no museu no primeiro semestre de 2016 e as duas restantes na biblioteca no segundo semestre. Um ônibus fretado buscava e levava os estudantes a suas escolas.

Ao final da primeira e terceira palestras, os estudantes retornaram para a escola, enquanto que ao final da segunda e quarta palestra, eles permaneceram para o lanche e passeio no museu e na universidade. No museu, as visitas foram guiadas pelos monitores, que ao questionar os estudantes observaram que a maioria deles não tinha visitado ou desconhecia a existência do museu na cidade. No segundo semestre, os estudantes foram recebidos por funcionários e conduzidos a um passeio pela biblioteca e pelos laboratórios de pesquisas de química. Nessas visitas, os estudantes puderam relacionar 
os conceitos aprendidos e as discussões sobre a Ciência e o cientista, realizados durante as palestras, aos aspectos apresentados pelos estudantes de pós-graduação e técnicos dos laboratórios que mostraram equipamentos, tempo demandado para o desenvolvimento das pesquisas e composição do grupo de pesquisa. A Figura 1 ilustra diferentes momentos das palestras.

Para avaliação da relação entre a participação das palestras de química (P1, P2, P3 e P4) e a crença na autoeficácia, a coleta de dados foi acerca de três momentos distintos (M1, M2 e M3), como mostra a Figura 2.

Ao final do primeiro semestre, uma entrevista (E1) foi realizada com o objetivo de captar a autoeficácia dos estudantes antes de participarem das palestras (M1) e depois de participarem de duas palestras (M2). Uma vez que os mesmos sujeitos de pesquisa deveriam ser entrevistados em diferentes momentos ao longo do ano letivo, optouse por realizar a primeira entrevista ao final do primeiro semestre. Nesse momento, seria possível verificar quem participou das primeiras palestras e teria maiores chances de estar presente nas palestras seguintes. Ao referir-se ao momento M1, foi solicitado enfaticamente que os estudantes se remetessem ao início do ano letivo, antes de qualquer intervenção. Ao final do segundo semestre, outra entrevista (E2) foi realizada para avaliar qualquer indício de mudança quanto à percepção da capacidade para aprender química ao longo do ano (M3).

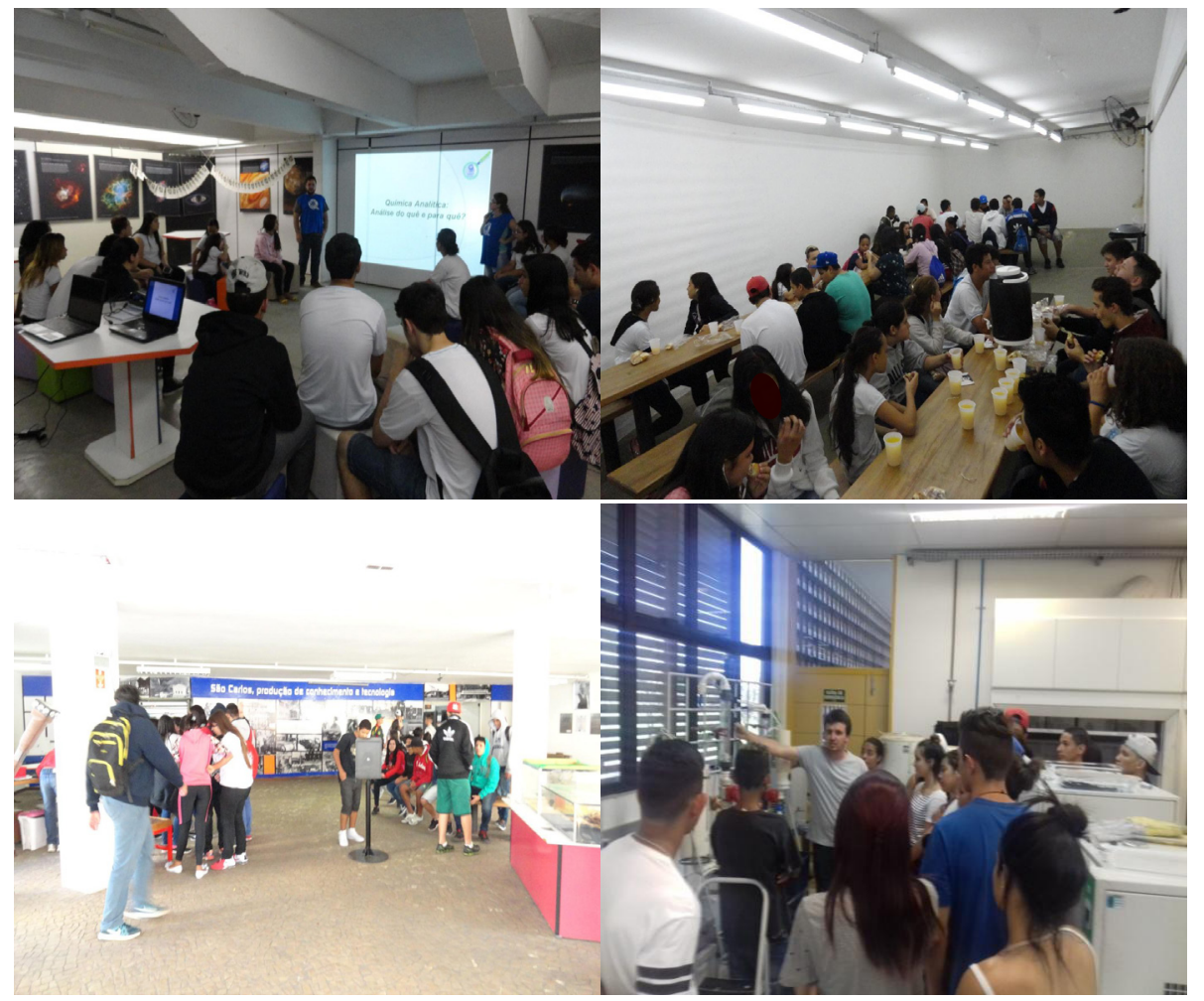

Figura 1. Da esquerda para a direita: apresentação das palestras, refeição, visitação ao museu e visitação aos laboratórios de pesquisa do IQSC. 


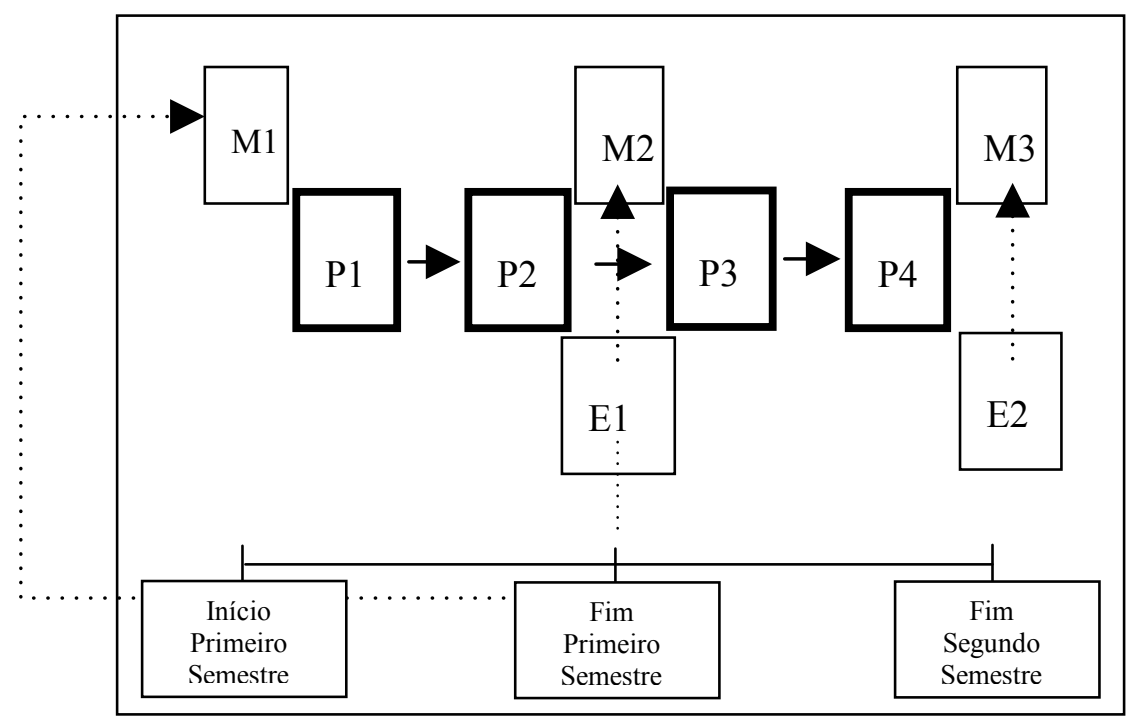

Figura 2. Esquema do estudo

Os sujeitos de pesquisa foram aqueles estudantes que interagiram e se destacaram durante a participação e aqueles que não se mostraram interessados em pelo menos 3 palestras. Ao aceitarem participar, todos foram informados sobre os objetivos da entrevista e a preservação da identidade. Um total de 30 estudantes e os três professores participaram das entrevistas E1 e E2, divididos de acordo com a escola (Tabela 1).

Tabela 1. Distribuição do número de participantes de acordo com a escola nas palestras e nos momentos de coleta de dados

\begin{tabular}{lcccc}
\hline Palestra & Número total de estudantes & \multicolumn{3}{c}{ Número de estudantes por escola } \\
\hline P1 & & A & B & C \\
\hline P2 & 133 & 44 & 58 & 31 \\
\hline P3 & 154 & 39 & 71 & 44 \\
\hline P4 & 110 & 28 & 55 & 27 \\
\hline E1 e E2 & 115 & 31 & 51 & 33 \\
\hline
\end{tabular}

Como evidenciado na Tabela 1, o número de estudantes entrevistados das escolas A, B e C foi 9, 8 e 13, respectivamente. Esses números superaram 10\% da amostra total como recomendado por Fraser e Gondim (2004) para pesquisas qualitativas.

Os estudantes foram identificados de acordo com a escola. Os estudantes da Escola A foram identificados por EA1, da Escola B por EB1 e da Escola C por EC1 e assim por diante. Os professores da Escola A foram identificados por Professor A, da Escola B por Professor B e da Escola C por Professor C.

As entrevistas com os estudantes duraram por volta de 20 minutos e foram realizadas na escola. As dos professores duraram por volta de 40 minutos e ocorreram 
em horários livres ou durante a Aula de Trabalho Pedagógico Coletivo (ATPC).

\section{Instrumentos}

O presente estudo fez parte de um projeto de pesquisa maior envolvendo a análise das palestras com base na Teoria da Autodeterminação. Desse modo, questionários sobre a motivação intrínseca, autoderminação, motivação por nota, motivação pela carreira e autoeficácia foram aplicados. Com base nos fatores destes questionários, um roteiro de entrevista, para que os pesquisadores pudessem discuti-los mais profundamente, foi criado. Todos os instrumentos foram validados no estudo piloto, tendo sido verificadas a pertinência das perguntas e a correspondência das respostas. $O$ presente estudo correspondeu, portanto, a um recorte deste projeto, limitando-se a analisar, explorar e discutir as respostas às entrevistas semiestruturadas relacionadas à crença na autoeficácia, com base na Teoria Sócio Cognitiva.

Na primeira entrevista dos estudantes (E1), havia perguntas sobre M1 como "Antes de participar das palestras, você acreditava na sua capacidade para aprender química? Por quê?" e sobre M2 como "Você se sente mais, menos ou igualmente confiante na sua capacidade para aprender química depois de participar das duas primeiras palestras? Por quê??".

Na segunda entrevista dos estudantes (E2), perguntou-se sobre M3: "Você se sente mais, menos ou igualmente confiante na sua capacidade para aprender química depois de participar de três ou quatro palestras? Por quê??".

Além das perguntas específicas sobre a autoeficácia, perguntas que permeiam o assunto e poderiam contribuir para a análise do estudo também foram realizadas como idade; em qual(is) escola(s) o aluno estudou no ensino fundamental; sua satisfação com a estrutura e recursos da escola e apoio familiar para estudar. O entendimento do ambiente escolar e contexto em que os estudantes estão inseridos pode contribuir para a compreensão sobre o quanto as palestras de divulgação científica impactaram ou não a crença na autoeficácia dos estudantes.

As entrevistas foram gravadas e posteriormente transcritas. Para a análise qualitativa, realizou-se a leitura das entrevistas na íntegra e a categorização simples pela separação dos trechos que correspondem ou permeiam o assunto autoeficácia. A análise ocorreu inicialmente de forma isolada e, em seguida, os autores discutiram e chegaram a um consenso de categorias.

\section{Resultados e Discussão}

\section{A autoeficácia dos estudantes}

Ao serem questionados sobre se acreditavam na capacidade de aprender química antes de participarem das palestras (M1), 13 estudantes responderam que sim, 14 
responderam que não acreditavam e 3 responderam que acreditavam pouco.

A análise das justificativas dos estudantes deu origem a categorias direta e indiretamente relacionadas à crença na autoeficácia, como:

- dificuldade para entender a química: respostas que abordaram a complexidade da química ou dificuldade para aprendê-la;

- falta de interesse: respostas que abordaram a falta de afeição pela química ou de disposição para aprendê-la;

- falta de confiança na capacidade de aprender: respostas que especificamente mostram a crença na incapacidade de aprender química.

- preocupação com o julgamento dos outros: respostas focadas na preocupação ou medo de comparações e julgamentos externos a respeito da capacidade de aprender química;

- crença na capacidade de aprender: respostas que especificamente mostraram a crença na capacidade de aprender química.

- esforço: respostas que mostraram o empenho e dedicação do estudante para aprender a química;

- interesse: respostas que focaram na afeição e entusiasmo pela química ou na disposição para aprendê-la.

A Tabela 2 mostra as categorias e frequências dessas respostas.

Tabela 2. Categorias e frequências segundo a pergunta "Você acreditava na sua capacidade de aprender química antes de participar das palestras? Por quê?"

\begin{tabular}{|c|c|c|c|}
\hline $\begin{array}{l}\text { Crença na } \\
\text { autoeficácia }\end{array}$ & Distribuição por escola (\%) & Categoria e frequência & Frequência $^{\star}(\%)$ \\
\hline \multirow{3}{*}{ Não (n=14) } & \multirow[b]{2}{*}{$\mathrm{A}=44,44$} & $\begin{array}{l}\text { Dificuldade para } \\
\text { entender a química }\end{array}$ & $43,33(n=13)$ \\
\hline & & Falta de interesse & $16,67(n=5)$ \\
\hline & $\mathrm{B}=62,50$ & Falta de confiança na & $3,33(\mathrm{n}=1)$ \\
\hline \multirow[t]{2}{*}{$\operatorname{Um}$ Pouco $(n=3)$} & \multirow{2}{*}{$C=61,54$} & capacidade de aprender & \\
\hline & & $\begin{array}{l}\text { Preocupação com o } \\
\text { julgamento dos outros }\end{array}$ & $3,33(\mathrm{n}=1)$ \\
\hline \multirow{3}{*}{$\operatorname{Sim}(n=13)$} & \multirow{3}{*}{$\begin{array}{l}A=55,56 \\
B=37,50 \\
C=38,46\end{array}$} & $\begin{array}{l}\text { Crença na capacidade de } \\
\text { aprender }\end{array}$ & $23,33(n=7)$ \\
\hline & & Esforço & $20,00(n=6)$ \\
\hline & & Interesse & $6,67(n=2)$ \\
\hline
\end{tabular}

ॠrespostas foram distribuídas em mais de uma categoria e, portanto, a somatória das frequências é diferente de $100 \%$.

Entre os que responderam que não acreditavam ou acreditavam pouco, as categorias que emergiram da análise foram: dificuldade para entender a química $(n=13)$ "Tinha dificuldade com a matéria" (EA6); falta de interesse pela química (n=5) "Não tenho força de vontade de querer aprender" (EC7); falta de confiança na capacidade de aprender $(\mathrm{n}=1)$ "Tinha um pouco de medo" (EA7); e preocupação com o julgamento 
dos outros ( $\mathrm{n}=1)$ "Se eu vou errar assim e as pessoas falarem, "nossa, ele errou assim", ficar zoando, essas coisas" (EB6).

Entre os que responderam que acreditavam, havia os que se sentiam capazes de aprender ( $\mathrm{n}=7)$ "Todo mundo é capaz de aprender" (EA8); os que se consideravam esforçados $(\mathrm{n}=6)$ "Sempre quis bastante e estudava bastante" (EC2); e os que possuíam interesse $(\mathrm{n}=2)$ "Gosto bastante de exatas" (EA5).

Os valores das frequências de cada categoria superaram o total de respondentes porque em alguns casos as justificativas por sentirem-se confiantes ou não na capacidade de aprender química, enquadraram-se em duas categorias. Por exemplo, "As vezes acho meio difícil só que eu gosto" (EA4) - dificuldade para entender a química e interesse pela química; "Não entendia a maioria das coisas, não prestava muita atenção por causa que comecei a odiar" (EC12) - dificuldade para entender a química e falta de interesse e "Não entrava na mente, não sou das exatas, mas tento aprender" (EC6) - dificuldade para entender a química e esforço.

Observa-se também que, além de algumas justificativas enquadrarem-se em mais de uma categoria, por vezes, como no caso das falas de EA4 e EC6, elas são antagônicas, pois mesmo o estudante afirmando que acredita na sua capacidade para aprender química (coluna 1, Tabela 2), pode apresentar justificativas associadas tanto à crença positiva quanto negativa, sendo portanto, contabilizado em duas categorias (coluna 4, Tabela 2). Estes casos mostram a dificuldade em se captar com clareza tal constructo pela própria complexidade inerente a ele. Por vezes, os estudantes sentem-se incapazes, mas se esforçam ou acreditam em sua capacidade, porém apresentam dificuldades. Isso ocorre porque a autoeficácia não está diretamente relacionada à capacidade em si, mas a crença ou convicção na capacidade para aprender, o que para o próprio indivíduo é de difícil discernimento.

A constatação de que parte dos estudantes se sente incapaz ou pouco capaz de aprender química pode ser atribuída à forma como muitas vezes o ensino de química é conduzido, de modo que, mesmo antes de iniciar o Ensino Médio, os estudantes já carregam pré-conceitos, sentem-se desmotivados e incapazes de aprender. O ensino descontextualizado e limitado a apostilas pouco incentiva além da memorização de conceitos e fórmulas que, para o estudante, não possuem sentido e aplicação.

Pesquisas evidenciam que muitos estudantes têm dificuldade para compreender a química por esta ser de natureza abstrata e envolver conceitos complexos (Demircioglu, Aslan, \& Yadigaroglu, 2014). Além disso, grande parte dos estudantes muitas vezes é apresentada à química teórica e experimental de forma desconexa, sem ligação entre teoria e prática (Pauletti, 2012). Ainda para Demo (2007), o enfoque em aula e prova de modo reprodutivista e a falta de propostas alternativas tanto na escola pública quanto na escola particular torna a “(...) mediocridade escolar instrucionista um patrimônio comum de todas as redes brasileiras" (p. 203).

Segundo Novais (1999, p.7 citado em Pereira, 2014, p. 15) ao priorizar o conteúdo conceitual, o professor deixa de atentar-se para questões como: 
Os alunos estão aprendendo ou memorizando? E se o aluno não for continuar seus estudos na universidade (o percentual de alunos que concluem o ensino superior ainda é pequeno)? Com o tempo de que disponho, será que é importante garantir que os alunos estudem modelos orbitais, orbitais híbridos, ou qualquer outro assunto específico? Será que, se eu ensinar tudo o que cai nos exames vestibulares até o final do curso, meus alunos irão se sair bem nesses exames? Que competências e habilidades meus alunos podem adquirir ao estudar todos esses conceitos?

Em um segundo momento da E1 (M2) ao serem questionados sobre se acreditavam na capacidade de aprender química depois de participarem das duas primeiras palestras, 19 estudantes disseram estar mais confiantes, 10 estudantes igualmente confiantes e um estudante menos confiante.

A análise resultou nas categorias:

- nenhuma mudança observada: respostas em que os estudantes declararam que nada mudou em relação ao estudo e aprendizado da química após a participação das palestras;

- aumento do interesse: respostas que procuraram abordar o aumento do entusiasmo pelo estudo da química e do interesse para aprendê-la;

- melhor compreensão dos conceitos químicos: respostas em que os estudantes focaram as melhoria do aprendizado de química no campo conceitual;

- melhor compreensão sobre a química: respostas que abordaram o entendimento da química no campo da construção do conhecimento ou, ainda, melhor compreensão sobre a natureza da ciência;

- aumento do esforço: respostas focadas no aumento do comprometimento da química como disciplina ou empenho para aprendê-la.

- relação entre química e o cotidiano: respostas que relacionavam a química a fatos ou objetos utilizados no dia a dia;

- importância de saber química: respostas que mostraram o entendimento da química como importante seja para a profissão ou futuro;

- dificuldade para entender a química: respostas que mostraram que com a, ou apesar da, participação nas palestras o estudante apresenta ainda mais dificuldade para aprender a química.

As categorias emergentes e frequências estão apresentadas na Tabela 3.

Dentre aqueles que em M2 consideraram que a confiança na capacidade de aprender química não foi alterada com a participação das duas primeiras palestras $(\mathrm{n}=10$, igualmente confiantes), 6 estudantes já acreditavam na capacidade de aprender química em M1. Outros 4 estudantes, que não acreditavam na capacidade de aprender no início, mantiveram a mesma posição. Isso indica que dentre os 14 estudantes que alegaram não acreditar na capacidade de aprendizado em química em M1, 4 mantiveram a mesma posição após a participação nas duas primeiras palestras. Os 3 estudantes que disseram acreditar pouco na confiança para o aprendizado de química em M1, alegaram estar mais confiantes após as palestras. Ainda, dentre os 13 estudantes que já se consideravam 
capazes em M1, 6 não detectaram mudanças e outros 7 consideraram-se ainda mais confiantes em M2. A única alteração para o sentimento de menos confiança em M2 foi de um estudante que já não acreditava na capacidade de aprender em M1, alegando dificuldade para entendê-la: "Não consigo entender" (EC3).

Os três estudantes que se consideraram pouco confiantes em M1 e mais confiantes em M2 alegaram motivos como crença na capacidade de aprender química, relação entre química e o cotidiano, melhor compreensão sobre a química, aumento do interesse e melhor compreensão dos conceitos químicos, como evidenciado em suas respostas:

"Sinto que posso aprender; aprendemos novos conteúdos que vamos vivenciar"(EB6) - crença na capacidade de aprender química e relação entre química e o cotidiano.

"A química não é difícil de aprender, antes não pensava que seria tão interessante" (EC6) - melhor compreensão sobre a química e aumento do interesse.

"Consigo responder umas questões do professor sozinha, sem ajuda, é prova de que melhorei" (EC10) - melhor compreensão dos conceitos químicos.

Tabela 3. Categorias e frequências das respostas segundo a pergunta "Você acredita na sua capacidade de aprender química depois de participar das duas primeiras palestras? Por quê?" (continua)

\begin{tabular}{|c|c|c|c|}
\hline $\begin{array}{l}\text { Crença na } \\
\text { autoeficácia }\end{array}$ & Distribuição por escola (\%) & Categoria & Frequência $^{*}(\%)$ \\
\hline \multirow{3}{*}{$\begin{array}{l}\text { Igualmente } \\
\text { confiante }(\mathrm{n}=10)\end{array}$} & $A=55,56$ & \multirow{3}{*}{$\begin{array}{l}\text { Nenhuma mudança } \\
\text { observada }\end{array}$} & \multirow{3}{*}{$33,33(\mathrm{n}=10)$} \\
\hline & $B=12,50$ & & \\
\hline & $C=30,77$ & & \\
\hline \multirow{6}{*}{$\begin{array}{l}\text { Mais confiante } \\
(n=19)\end{array}$} & \multirow{6}{*}{$\begin{array}{l}A=44,44 \\
B=87,50 \\
C=61,54\end{array}$} & $\begin{array}{l}\text { Aumento do } \\
\text { interesse }\end{array}$ & $23,33(\mathrm{n}=7)$ \\
\hline & & $\begin{array}{l}\text { Melhor compreensão } \\
\text { dos conceitos } \\
\text { químicos } \\
\end{array}$ & $16,67(\mathrm{n}=5)$ \\
\hline & & $\begin{array}{l}\text { Melhor compreensão } \\
\text { sobre a química }\end{array}$ & $16,67(n=5)$ \\
\hline & & Aumento do esforço & $13,33(\mathrm{n}=4)$ \\
\hline & & $\begin{array}{l}\text { Relação entre química } \\
\text { e o cotidiano }\end{array}$ & $6,67(n=2)$ \\
\hline & & $\begin{array}{l}\text { Importância de saber } \\
\text { química }\end{array}$ & $3,33(\mathrm{n}=1)$ \\
\hline
\end{tabular}


Tabela 3. Categorias e frequências das respostas segundo a pergunta "Você acredita na sua capacidade de aprender química depois de participar das duas primeiras palestras? Por quê?" (continuação)

\begin{tabular}{lccc}
\hline $\begin{array}{l}\text { Crença na } \\
\text { autoeficácia }\end{array}$ & Distribuição por escola (\%) & Categoria & Frequência $^{*}(\%)$ \\
\hline $\begin{array}{l}\text { Menos confiante } \\
(\mathrm{n}=1)\end{array}$ & $\mathrm{A}=0$ & $\begin{array}{c}\text { Dificuldade para } \\
\text { entender a química }\end{array}$ & $3,33(\mathrm{n}=1)$ \\
\hline
\end{tabular}

*uma resposta pode ter sido distribuída em mais de 1 categoria e a categorização não incluiu os estudantes “igualmente confiantes", portanto, a somatória das frequências é diferente de $100 \%$.

A Tabela 4 mostra as categorias emergentes daqueles que consideravam estar mais confiantes na capacidade de aprender química.

Ao final do segundo semestre, ao participarem da entrevista E2 a referente ao terceiro momento, M3, 22 e 8 estudantes disseram estar mais confiantes e igualmente confiantes, respectivamente.

Dentre os igualmente confiantes $(n=8)$, cinco mantiveram a posição de que não observaram mudanças e continuavam confiantes na capacidade de aprender em relação a M2 da E1, enquanto três estudantes acreditavam não ter essa capacidade tanto em M1 quanto em M2 e mantiveram essa percepção em M3.

Como nos casos anteriores, a soma das frequências das categorias superou o número total de entrevistados que se classificaram mais confiantes $(n=22)$ devido à coincidência de mais de uma categoria na mesma argumentação, como em "Participei das palestras, vi a universidade, prestei atenção e pensei que quero isso para mim; dá vontade de aprender mais e pegar mais firme" (EC10) - aumento do esforço e aumento do interesse. Nesse exemplo, uma vez que as crenças de autoeficácia influenciam as escolhas de cursos de ação, o estabelecimento de metas, quantidade de esforço e perseverança em busca dos objetivos, tem-se indícios do aumento da eficácia que foram, pelo estudante, atribuídos à participação da palestra.

Assim, observa-se de modo geral, que ao se comparar o quadro inicial e final, apenas três estudantes que disseram "não" no início, continuaram não acreditando na capacidade de aprender química, sendo um estudante de cada uma das três escolas. Dentre os 13 estudantes que disseram "sim" no início, 6 não observaram mudanças, ou seja, continuaram acreditando na autoeficácia. O restante $(n=21)$ observou aumento da autoeficácia ao longo da participação das palestras. 
Tabela 4. Categorias e frequências das respostas segundo a pergunta "Você acredita na sua capacidade de aprender química depois de participar de três ou quatro palestras? Por quê?”

\begin{tabular}{|c|c|c|c|}
\hline $\begin{array}{l}\text { Crença na } \\
\text { autoeficácia }\end{array}$ & Distribuição por escola (\%) & Categoria & Frequência $^{*}(\%)$ \\
\hline \multirow{3}{*}{$\begin{array}{l}\text { Igualmente } \\
\text { confiante }(\mathrm{n}=8)\end{array}$} & $A=33,33$ & \multirow{3}{*}{$\begin{array}{l}\text { Nenhuma mudança } \\
\text { observada }\end{array}$} & \multirow{3}{*}{$26,67(\mathrm{n}=8)$} \\
\hline & $B=25,00$ & & \\
\hline & $C=23,08$ & & \\
\hline \multirow{5}{*}{$\begin{array}{l}\text { Mais confiante } \\
(\mathrm{n}=22)\end{array}$} & \multirow{5}{*}{$\begin{array}{l}A=66,67 \\
B=75,00 \\
C=76,92\end{array}$} & $\begin{array}{l}\text { Melhor compreensão } \\
\text { dos conceitos químicos }\end{array}$ & $30,00(n=9)$ \\
\hline & & $\begin{array}{l}\text { Melhor compreensão } \\
\text { sobre a química }\end{array}$ & $20,00(n=6)$ \\
\hline & & Aumento do esforço & $13,33(n=4)$ \\
\hline & & Aumento do interesse & $10,00(n=3)$ \\
\hline & & $\begin{array}{l}\text { Preocupação com o } \\
\text { julgamento dos outros }\end{array}$ & $3,33(n=1)$ \\
\hline
\end{tabular}

*uma resposta pode ter sido distribuída em mais de 1 categoria e a categorização não incluiu os estudantes "igualmente confiantes", portanto, a somatória das frequências é diferente de $100 \%$.

Em M3, mais estudantes passaram a se sentir ainda mais capazes de aprender química, sendo que as quatro principais causas foram as mesmas de M2.

$\mathrm{O}$ aumento de interesse foi abordado pela maioria dos estudantes que se sentiu mais confiante na capacidade de aprender química após a participação nas palestras, em M2, "Achei legal e interessante os conceitos" (EC6) e em M3, "Não teve peso nas costas, não foi obrigado, gera interesse maior" (EB4).

A química está envolvida em todos os setores produtivos e é de suma importância para o desenvolvimento econômico e tecnológico mundial. Entretanto, poucas pessoas reconhecem a relevância da química para vida, porque não conseguem relacionála a avanços em áreas como a medicina e meio ambiente (Santos, 2011). Tais fatores têm contribuído para causar desinteresse em estudantes do Ensino Médio que veem a química como difícil e distante da realidade, além de compartilharem uma imagem negativa dessa área, relacionando-a a desastres ambientais, poluição e problemas de saúde, causados por materiais tóxicos (Salta, \& Tzougraki, 2004; Santos, 2011; Teruya, Marson, Rezende, \& Viana, 2013). As palestras, por meio das pesquisas científicas da química, retrataram esses temas importantes para o meio ambiente e qualidade de vida de modo a despertar ou aumentar o interesse dos estudantes.

Por abordar conceitos e técnicas químicas, como substâncias, misturas, interação entre luz e matéria, separação de substâncias, entre outros, as palestras proporcionaram melhor compreensão dos conceitos químicos no que diz respeito à discussão numa perspectiva diferente da escola. No primeiro ano do Ensino Médio, os estudantes observaram o quanto aquilo aprendido é, de fato, aplicado e importante na busca por soluções de problemas. Por exemplo, em M2, "Consigo responder umas questões do professor sozinha, sem ajuda, é prova de que melhorei" (EC10) e em M3, "Cada aula da 
professora eu aprendo mais do que antes" (EB5).

Também foi constatado que o aumento da autoeficácia de alguns estudantes se deu pela melhor compreensão sobre a química, no que concerne à natureza dessa área do conhecimento. Em relação à esse aspecto, existem exemplos em M2: "Vi que não é um negócio muito chato como pensava; vejo a química de outro jeito" (EA7) e em M3, "A química não é tão complicada" (EB3). A palestra permitiu que os estudantes mergulhassem em diferentes momentos e profundidades no trabalho de químicos, das perguntas que motivam as pesquisas, levantamento de hipóteses e estabelecimento de metodologias, além dos desafios geralmente encontrados nesse processo. Mostrou-se a necessidade de investimentos, a composição heterogênea de laboratórios de pesquisas, a importância da discussão do trabalho em artigos e congressos, entre outros aspectos que facilitam a compreensão sobre a natureza da Ciência.

A categoria aumento de esforço é exemplificada em M2: "Porque fiquei mais interessado; pergunto e participo mais da aula, peço ajuda (EC2); Estou prestando mais atenção, fazendo as coisas como pedem (EC4); Agora tento aprender o que não gostava, tenho mais foco (EC8); Porque eu me interessei, eu senti vontade de saber mais, então dá vontade de ir atrás" (EA4) e em M3: "As palestras foram uma ajuda para mim, um esforço para me ajudar" (EC13)

Em M2, as categorias restantes, relação entre química e o cotidiano, "A palestra vem para me ajudar a aprofundar mais em certos assuntos diários, remédio, comida" (EB5) e importância de saber química, "Preciso para a profissão, futuro, saber é importante" (EB8), estão relacionadas entre si e às categorias anteriores, especialmente aumento do interesse e melhor compreensão sobre a química. Isto porque os temas das pesquisas apresentadas e de muitas outras desenvolvidas nas universidades voltam-se para interesses ambientais, econômicos, industriais, da área da saúde, entre outros, que são benéficos à comunidade da cidade e região e que, quando percebidos pelos estudantes, contribuem para a valorização da química e da autorregulação da aprendizagem através de formas mais autônomas de motivação extrínseca como podemos observar em "Preciso para a profissão, futuro" e através da internalização, como em "saber é importante".

Por outro lado, o único estudante que disse estar menos confiante em M2 relatou estar mais confiante em M3. Sua resposta foi enquadrada na categoria preocupação com o julgamento dos outros, por dizer "Mas tenho vergonha de perguntar coisas que não entendo" (EC3), o que afeta a confiança na capacidade de aprender química.

Um dos fatores que podem ter contribuído para o fortalecimento da crença na autoeficácia foi a apresentação em espaços de educação não formal. Tanto os professores como a maioria dos estudantes nunca haviam visitado o museu e lá, de um modo descontraído, além de participarem das diversas atividades das palestras de química, realizaram experimentos de Física, observaram e tocaram fósseis da seção de Paleontologia e participaram de exposições itinerantes da área da Biologia.

O desenvolvimento de parte das palestras no museu pôde inserir o estudante em um ambiente que envolve pluralidade de sujeitos, onde se ensina e aprende propositalmente, 
porém sem a configuração de espaço, tempo e progressão tão conhecidos na educação formal. Umas das características consideradas vantajosas da educação não formal é o modo de interação com o público ou frequentadores. O contato visual, muitas vezes corporal, e a participação ativa nas atividades oferecidas, além das experiências sociais, são motivadores e despertam a curiosidade (Axelsen, 2006; Studart, 2000). Isso fortalece ainda mais o ensino e a aprendizagem e o distingue muitas vezes do processo sistematizado oferecido nas escolas, visto muitas vezes como desmotivador. De acordo com Martins, et al. (2013) muitos educadores têm inserido atividades de educação não formal no currículo escolar na busca de tornar a construção do conhecimento mais criativa, prazerosa e dinâmica.

Por outro lado, a realização de parte das palestras na universidade teve como propósito inserir o estudante no ambiente de estudo e desenvolvimento de pesquisas científicas. $\mathrm{O}$ contato com a rotina de graduandos, pesquisadores e tecnologias comuns no ambiente universitário, além de diminuir as visões distorcidas sobre o que a universidade é e faz, pode também despertar o interesse dos estudantes e motivá-los para o aprendizado tanto de química, através das pesquisas apresentadas, quanto de outras disciplinas, para que no futuro queiram ingressar em uma universidade.

Além de usar o espaço da universidade, em uma das visitas os estudantes foram conduzidos aos laboratórios de pesquisas e, ao serem recebidos por estudantes e técnicos responsáveis, puderam discutir a importância de algumas técnicas e equipamentos, assim como perguntar ainda mais sobre o trabalho de um grupo de pesquisa, por quem é formado, as trocas de ideias e resultados com outros grupos do Brasil e exterior, a necessidade de investimentos, entre outros aspectos que, muitas vezes, só são compreendidos após o ingresso na universidade e envolvimento em pesquisas.

Outro aspecto fundamental da palestra foi a participação de estudantes da licenciatura na apresentação e condução das atividades. Isto porque eles incluíram em suas falas:

-suas trajetórias, desde o estudo em escolas públicas até o ingresso na universidade pública, mostrando que já estiveram em uma situação semelhante à dos estudantes participantes, mas que com empenho superaram as adversidades;

-algumas experiências da graduação, destacando os auxílios que a universidade disponibiliza, como o auxílio transporte, moradia, livros, alimentação, entre outros;

-possibilidade de, durante o curso superior, participar de projetos e desenvolvimento de pesquisas com bolsas de estudo financiadas por agências de fomento; -o fato de a vida de um pesquisador ser semelhante a de outros profissionais, pois envolve o interesse e dedicação pelo que faz e inclui ter família, amigos e horas de lazer.

Essas discussões, especialmente quando conduzidas por alguém que vivencia a formação em uma universidade e já esteve em situação semelhante à dos estudantes participantes, parecem ser fundamentais para desmistificar a crença na inacessibilidade à universidade pública por estudantes da escola pública e também para romper com a visão do cientista como um gênio, sem vida social e interesse por outros assuntos. Ao 
participarem das palestras, os estudantes passam a acreditar mais na própria capacidade, à medida que conheceram exemplos semelhantes e entenderam que se estabelecerem o ingresso à universidade como objetivo e se esforçarem para tanto, poderão ser capazes.

\section{A autoeficácia dos estudantes segundo os professores}

A atuação do professor é fundamental para o ensino cujo conhecimento seja construído junto ao estudante de modo que faça sentido e possua aplicação frente a problemas, conflitos ou situações diárias. No entanto, é comum a observação do ensino instrucionista, focado no conteúdo conceitual. Tal condução do ensino, somada à dificuldade com os conteúdos pode resultar em desmotivação. Além disso, a pouca apreciação da química na fase escolar pode estender-se à vida adulta, mesmo quando o estudante ingressa no Ensino Superior e em cursos correlatos (Ferrell, \& Barbera, 2015).

A priorização dos conceitos e consequências para os estudantes é reconhecida e pontuada pelo Professor C em M3 ao comparar sua percepção sobre as palestras com a rotina da sala de aula:

"Em sala de aula a dinâmica é um pouco diferente, né? Porque lá a gente tava (sic) fora de sala fazendo uma atividade investigativa e experimental, né? E a sala de aula envolve um conteúdo mais teórico, às vezes mais pesado. Então, nesse sentido eles têm atenção, mas é diferente a maneira de como eles dão assim na atenção, né? Ali (na palestra) a coisa acontece de maneira mais espontânea. Eles querem, devido à curiosidade que eles têm, saber mais, assim, então parte muito mais deles, nesse sentido. Ali (na escola) eu tenho que conduzir, entendeu? Então, porque o conteúdo às vezes é mais teórico, mais pesado, às vezes é mais desgastante, né, mas eu acho que foi nesse sentido."

O Professor A em M2 também destacou que:

"Eu acredito que eles se divertiram bastante, não sei. (...) Eu acho que sair da escola, né? Ãhn... você não ter uma obrigação de acertar, de errar, né? De ter nota, vamos dizer assim. Ãhn... e também assuntos diferentes. Então, essas coisas contribuem."

O Professor B atribuiu a atenção e comportamento dos estudantes única e exclusivamente ao fato de estarem em um espaço diferente da escola:

"Atenção foi, no sentido de saber que estão num lugar que não é a escola. Acho que mais por um pouquinho de educação, né? Que eles têm. (...) É. Eu diria que acho que a educação, né? Assim, não vou dar o relaxo que dou na sala de aula. (...) Agora, a participação, eu acho que são poucos."

É possível observar que os três professores mencionaram o fato de as palestras terem ocorrido fora da escola como um aspecto primordial para despertar a atenção dos estudantes e mudar o comportamento deles em relação ao comportamento em sala de aula. O Professor $\mathrm{C}$ discutiu a espontaneidade dos estudantes ao participar das atividades experimentais e o Professor A discutiu sobre a diferença dos assuntos abordados e a ausência de pressão com relação à existência de avaliação e notas.

Para Gohn (2016), a presença da educação não formal na fase de escolarização potencializa a aprendizagem e dá espaço para aspectos não contemplados pelas estruturas 
curriculares. Segundo a autora, “(...) pelo fato de ser menos estruturada e mais flexível, a educação não formal consegue atingir a atenção e o imaginário dos jovens" (p. 71).

Ainda sobre a atenção e comportamento dos estudantes dentro e fora da escola, o Professor B ainda destaca em M3:

"Eles não têm vontade. (...) Ah, alguns têm. Poucos. (...) "Infelizmente. O valor do estudo, para eles não tem valor, não é valor, né? Eh... estudar para eles talvez signifique o ter dinheiro, não eu ter conhecimento, né? Eh... acho que é bem brasileiro, isso também, né? Não ter esse valor do estudo como algo primordial na vida da gente, né? Conhecimento em qualquer momento é bom."

Nesse trecho observa-se a crença do professor tanto na falta de vontade quanto na desvalorização generalizada dos estudos por parte dos estudantes. Como mostrado na Tabela 1 , no início do ano letivo, parte dos estudantes $(37,5 \%)$ já se sentia capaz e interessada no aprendizado de química, contrariamente ao que diz o professor.

Por outro lado, um estudo de Severo e Kasseboehmer (2017) mostrou divergência entre a motivação que os estudantes possuem de fato e a relatada pelos professores, ressaltando que a própria percepção de motivação pode ser pouco conhecida ou mal interpretada pelos professores que, muitas vezes, possuem percepções tecnicistas sobre o que é ser um bom estudante e acabam por declará-los como desmotivados e indisciplinados.

O mesmo professor, mais adiante associou a situação escolar a problemas sociais: "Para mim, é social, social não ajuda. A história de vida deles é pesada (...) E... para mim, é social e familiar, né? E eles têm que se defender sozinho na vida, que jeito? É... até compreensivel, né? Entre aspas, né?"

Observa-se a atribuição da desmotivação a fatores como cultura, família e sociedade. Do mesmo modo que a cultura e sociedade acabam por influenciar o comportamento dos estudantes, como o professor comentou, de acordo com a Teoria Sócio Cognitiva (Bandura, 2001), a aprendizagem ocorre devido à interação dos indivíduos e meio ambiente, de modo que não somente família e amigos, mas também os professores e suas ações são elementos que atuam sobre o indivíduo, influenciando a aquisição, retenção ou abandono de comportamentos.

É diante desse diagnóstico que se justifica o emprego de estratégias para a elevação da crença na autoeficácia do estudante, entre outros componentes motivacionais através de metodologias ativas desenvolvidas dentro e fora da escola.

Ao acompanharem os estudantes durante a palestra e ao longo do ano, os professores relacionaram as mudanças percebidas às mesmas categorias emergidas das entrevistas dos estudantes, como aumento do interesse, esforço, curiosidade e compreensão dos conceitos químicos.

Em M2, para o Professor C foi perceptível a mudança dos estudantes sobre autoeficácia especialmente com relação ao conteúdo conceitual: "De aprender química, exatamente, acho que isso daí, né, um conceito, assim, eles se sentem mais capazes". Ao ser questionado sobre qualquer mudança percebida ao longo do ano, o Professor C 
pontuou novamente: "Foram poucas, mas elas apareceram. Principalmente de química, né, experimentos de química, como eu falei já dou aula de química e de física, tanto que as notas foram maiores em química. Eles, não sei por que, não sei, eles tiveram esse ano um desempenho, um rendimento escolar melhor."

Bryan et al. (2011) observaram que a autoeficácia era o componente que apresentava maior relação com desempenho escolar. Tal observação é consistente com a Teoria Sócio Cognitiva que enfatiza o papel central da crença na autoeficácia para a autorregulação da motivação. Essas crenças correlacionam-se com uso de estratégias e autorregulação, facilitando o engajamento cognitivo. Implantar tais crenças pode conduzir ao maior uso de estratégias cognitivas que, por sua vez, terão reflexos positivos no desempenho final (Pintrich, \& De Groot, 1990).

Em M3, sobre a utilidade que os estudantes passaram a atribuir a química e a relação com as palestras, o Professor C disse: "Eu acho que sim, sabe por quê? Porque eles questionaram mais coisas, inclusive de Facebook, disso, aquilo, falar, "ó, vamos fazer em sala de aula", aí "como faz isso", "Em que isso vai ajudar na minha vida?". Da importância de aprender, né, entender um pouco do mundo e da importância social, né, que a química tem, né? Você vê que vai produzir um remédio, vai, né, vai produzir um produto novo, uma tecnologia nova, e isso é coisas que eles vivenciam no cotidiano que o conhecimento tá ali, né? Que eles precisam entender. Então, nesse sentido, eles começaram a perceber mais a importância da química. Principalmente nesse sentido."

Sobre a relação que os estudantes começaram a fazer entre a química e algumas profissões, o mesmo professor comenta: "Eles já começam a pensar: "olha, eu posso trabalhar com isso", "tem esse caminho, olha, eu não conhecia isso", entendeu? Quando foi apresentado lá algumas profissões, né, que a química, ela transcende várias profissões, várias áreas de conhecimento, então nisso eles começaram a perceber que existe isso, que é um caminho, né? Não que... alguns têm uma afinidade maior com aquilo, gostam mais, né, então para mim é isso."

Observa-se, nos trechos acima, que a divulgação científica parece ter cumprido seu papel no tocante a oportunizar a compreensão sobre a importância da química para a ciência, tecnologia e sociedade, bem como sobre química como profissão, mudanças bastante enfatizadas pelo Professor C.

Em M2, o Professor A fez as seguintes observações sobre o esforço dos estudantes: "Ó, teve (sic) alunos que tiveram mudança (de comportamento), teve (sic) alunos que não tiveram mudança. A mudança que eu percebi foi que eles perguntavam mais, algumas vezes, até relacionava com a questão da palestra. Eu percebi que eles, faziam as atividades mais, com mais vontade. E com aqueles que não mudaram, eles já vinham para escola e ficavam simplesmente sem fazer nada. E continuaram com a mesma postura."

Em M3, sobre a observação de mudanças ao longo do ano, o Professor C também associou a capacidade ao esforço dos estudantes: "Modificou. Como eu falei, tá muito diretamente relacionado com o esforço. "Ah, eu tenho esforço porque eu sei que eu vou conseguir". Então quando eu coloco ou uma situação investigativa ou quando eles sentam 
juntos, que vão ter que descrever um fenômeno ou um conceito, eles já se sentem mais capazes, né? Então acho que nesse sentido, também veio reforçar essas palestras, né, porque eles se sentiram capazes em montar o experimento, em medir, em fazer, em tentar argumentar e por que mudou de cor, por que não mudou de cor, por que isso ficou mais forte, por que isso não, o que é cromatografia, entendeu?"

$\mathrm{O}$ fato de o esforço dos estudantes ter aumentado de modo perceptível pelos professores é um indício do aumento da crença na autoeficácia. De acordo com Pintrich e De Groot (1990), as crenças de autoeficácia influenciam o aumento do esforço aplicado e da persistência diante de desafios e obstáculos. Bandura (2001) também discute que os desafios que as pessoas escolhem enfrentar, o esforço que despendem e o tempo que persistem diante de fracassos e obstáculos compõem uma das bases da crença na autoeficácia.

$\mathrm{Na}$ fala do Professor $\mathrm{C}$ também fica clara a importância que ele atribuiu ao papel da experimentação nas palestras de divulgação científica da química. Cordeiro, Vaciloto, Virtuoso e Kiill (2013) discutem a experimentação como importante para despertar o interesse do estudante ou ajudá-lo a desenvolver suas ideias e o senso de investigação. O Professor C demonstrou perceber e entender o papel do experimento de desenvolver habilidades de investigação e análise. Tal percepção vai contra os resultados obtidos por Cordeiro et al. (2013) em um estudo desenvolvido no Brasil com 25 professores das áreas de Biologia, Física, Química, Matemática e Ciências, em que foi constado que a maioria entende o papel da experimentação para comprovar, testar e observar a teoria, compreensão esta já obsoleta.

Sobre o comportamento dos estudantes ao longo do ano, o Professor B enfatizou em M3:

"O interesse deles mudou. O interesse, a curiosidade. Às vezes, é algo já que eles gostavam, né? E que essa palestra, isso, levar para uma universidade, que eles não tinham nem noção, né? (...) Mas eu senti, sim, que aqueles que já tinham algo com eles, um interesse, que aquilo abriu, porque a maneira de se colocar, toda aula, quando eu entro, eles vêm querer saber alguma coisa. Mudou. Mas como eu falei, para poucos. E outra, poucos porque essa área de matemática, química e física também não é para muitos mesmo, né? Não é uma maioria que se interessa".

Nesse trecho, nota-se que o professor observou mudanças, especialmente no interesse dos estudantes. Entretanto, ele afirmou que isto ocorreu com poucos e que, possivelmente, eles já tinham certa predisposição para tanto, sendo que as palestras aumentaram esse interesse. Nota-se também a crença na vocação ou "dom" para uma área em relação à outra, ao afirmar que a área das exatas não é para todos.

Sobre se a participação das palestras de divulgação científica da química ajudou de alguma maneira, em M3 o Professor B disse: "Sim, tanto que quando a gente voltava das palestras, eu falava, dizia para eles, eu cobrava isso deles, "ó, tô (sic) anotando tudo e vai ter um..." É até feio falar isso, mas é o que eu fazia, tá? "Vai ter um questionário, eu vou perguntar o que foi dito lá, valendo nota, porque aquilo não foi para vocês irem tomar 
um ar, comer um lanche, vir embora. Aquilo teve um conteúdo, que é o que me interessa."

Ao ser questionado se o fato de ter cobrado alguma coisa depois foi o que motivou os estudantes a participarem, o Professor B respondeu: "Para quem queria, não. Para quem queria, foi, foi de bom gosto, de bom grado, querendo ouvir. Agora, para os outros, a gente tem que, né? Porque senão fica muito mais disperso, né? Porque eu acho eles muito dispersos. Muito, muito, muito. Acho não, são".

Sobre o quanto a decisão de incluir a participação das palestras na avaliação geral, o Professor C disse: "Claro que nem todos. A gente sabe que numa sala de aula nem todos têm a mesma dedicação, o mesmo empenho, a mesma motivação, vamos dizer assim, para fazer atividade. E com o intuito de que todos participassem, então eu realmente decidi dar um peso, ponderar isso na média, entendeu? Porque olha, vai participar, vai lá, vai tentar, vai ter, só que na dinâmica da aula, da situação, o que eu percebi? Que o que pesou mais não foi isso. Foi o que? Eles conversarem entre eles, tentarem entender o experimento, aquilo era novo para eles de alguma maneira, eles estão no primeiro ano do ensino médio, fizeram, devem ter feito algum tipo de experimento em ciências e tudo mais, mas não de uma maneira e da abordagem que foi. (...) Claro que teve um certo peso, né? Eu atribuir uma nota de certa maneira tá regulando eles para participarem, mas não foi maior do que o envolvimento que eles tiveram."

No início do estudo, todos os estudantes foram advertidos sobre a não obrigatoriedade de participação das palestras, de modo que o pesquisador não iria interferir na avaliação do desempenho escolar. Entretanto todas as escolas e professores tiveram liberdade de conduzir como preferissem suas aulas durante o período de participação, uma vez que o objetivo do estudo era avaliar o efeito das palestras e discutilo conforme a atuação de cada professor, sem, entretanto, controlá-lo.

Dois dos professores (B e C) optaram por incluir a participação dos estudantes e discussões sobre os temas das palestras na avaliação escolar. Nesses casos, a avaliação ou atribuição de nota foi promovida com objetivo de controlar ou regular as ações dos estudantes de modo a conduzi-los a ir e participar da palestra. Tal regulação é característica do professor controlador (Bzuneck, \& Guimarães, 2007; Severo, \& Kasseboehmer, 2017). Nesse caso, o controle é reforçado quando a avaliação é tratada de modo normativo, com objetivo classificatório ou de hierarquização do desempenho dos estudantes. Como Bzuneck e Guimarães (2007) discutiram, embora estilos motivacionais altamente controladores e altamente promotores de autonomia não possuam qualquer correlação, tais estilos podem coexistir e prevalecer vez ou outra na atuação do professor em diferentes situações em sala de aula.

Apesar do controle da participação promovido pelo professor, em todos os casos, eles afirmaram que não foi isso que determinou a participação, envolvimento e mudança dos estudantes, especialmente, daqueles que mesmo antes das palestras já apresentavam disposição para o estudo e aprendizado de química.

De acordo com os três professores, os estudantes são motivados por atividades extraclasse, interativas, que entusiasmam, envolvam a manipulação de objetos, 
experimentação e o contato com informações e fatos não apresentados nas apostilas do Ensino Médio. Entretanto, por mais que os professores valorizem e aceitem parcerias com a universidade, declararam ter dificuldade ou não levar inovações, usar metodologias ativas ou desenvolver atividades fora da escola. Tal dificuldade pode estar relacionada à frustação e à exaustão dos professores decorrentes do baixo reconhecimento profissional e social, do aparente desinteresse dos estudantes e da alta exigência por uma formação ambiental, social, política e extremamente conteudista (Kasseboehmer, Hartwig, \& Ferreira, 2015).

Friedman e Kass (2001), Goya et al. (2008) e Skaalvike Skaalvik (2010) evidenciam que, mesmo frente a toda demanda e com tempo reduzido de aula, é o professor que, ao ter contato periódico com o estudante, interferirá mais profundamente no envolvimento e aprendizado. Assim, as palestras, embora possam cumprir inúmeros objetivos educacionais e preencher várias lacunas do ensino escolar, por terem frequência reduzida em comparação com a atuação do professor em sala de aula, podem não conseguir superá-lo em relação à promoção da autoeficácia, especialmente quando o ensino for mais tecnicista e distante do estudante.

Quando questionado em M3 sobre a curiosidade e interesse dos estudantes, o Professor A também relatou pouca abertura e contato com a turma: "Pode até ser que mudou alguma coisa, mas eu não consigo detectar porque não existe um diálogo. Né? Eu não consigo conversar com eles. Eu dou mais atenção para quem tá fazendo."

A relação professor-estudante pode ter contribuído para que a desmotivação de uma pequena parte dos estudantes no início do estudo tenha se mantido enquanto que o restante, que já confiava na capacidade de aprendizado, permaneceu com a crença ou teve a autoeficácia ainda mais elevada. A carência de metodologias ativas, o distanciamento e mau relacionamento com os estudantes, no caso dos professores A e $B$, podem ter influenciado a estagnação da crença na autoeficácia ao longo do ano para os estudantes menos confiantes, apesar das palestras ou de outras atividades que possam ter desenvolvido eventualmente na escola ou fora dela.

O encorajamento de estudantes para o engajamento em situações de aprendizado de química e de outras disciplinas de ciências e para o ingresso no Ensino Superior é importante porque muitas vezes os estudantes não possuem a motivação para tanto ou desconhecem o próprio potencial nessas áreas (Bryan et al., 2011). Para tanto, é importante o envolvimento dos professores que além de motivá-los em um processo longitudinal, também possam diagnosticar fatores motivacionais periodicamente. Uma possibilidade é o questionamento dos estudantes em diferentes momentos ao longo do ano através de questões motivadoras sugeridas por Bryan et al. (2011) a respeito da autoeficácia e autorregulação. Tal acompanhamento pode contribuir para a tomada de uma postura docente mais ativa e motivacional.

\section{Considerações finais}

O objetivo deste artigo foi avaliar a contribuição de palestras de divulgação 
científica da química quanto à promoção da crença na autoeficácia em estudantes do primeiro ano do ensino médio.

O fato de os estudantes relacionarem a participação nas palestras, em conjunto com as visitas ao museu e à universidade, a fatores como aumento do interesse pela química, melhor compreensão dos conceitos químicos e sobre a natureza da química, bem como aumento do esforço aplicado para o aprendizado, representa indícios de fortalecimento das crenças de autoeficácia. O mesmo foi observado pelos professores participantes, à medida que aprofundaram o olhar para suas turmas e notaram particular aumento do esforço e interesse de alguns estudantes, embora não tenham observado mudanças em toda turma.

Entre os aspectos das palestras que contribuíram para o resultado, destacam-se os temas das pesquisas, as dinâmicas das apresentações, as visitas aos espaços não formais utilizados e a formação dos apresentadores. Os fatos de as palestras abordarem pesquisas científicas atuais e desenvolvidas na própria cidade, envolverem a experimentação e acontecerem na universidade foram os mais citados pelos professores.

Embora as palestras de divulgação científica da química tenham sido elaboradas e conduzidas por integrantes da universidade, o papel do professor de química também é importante nesse processo. Como fator limitante, tem-se o hábito dos professores de avaliar todas as atividades no sentido normativo, indicando o prevalecimento da promoção do controle sobre a promoção da autonomia dos estudantes. O distanciamento e falta de diálogo entre professores e estudantes também são fatores limitantes para o diagnóstico, intervenção e acompanhamento das turmas, uma vez que o professor pouco observa seus estudantes e pouco encara a docência como uma atividade de pesquisaação.

Outro aspecto que pode ter interferido no resultado e deve ser considerado é a realização da primeira entrevista ao final do segundo semestre. Essa decisão foi tomada pela opção metodológica de serem entrevistados aqueles que se envolveram muito ou muito pouco nas palestras. Portanto, uma observação dos estudantes seria necessária antes de se escolher os sujeitos de pesquisa. $\mathrm{O}$ fato de os estudantes terem participado em duas palestras antes da primeira entrevista pode ter influenciado a crença na autoeficácia e, consequentemente, as respostas sobre M1. Estudos posteriores devem buscar alternativas para captar com mais fidedignidade a realidade inicial dos estudantes. Uma possibilidade é trabalhar com menos escolas ou turmas menores de estudantes a fim de manter o acompanhamento qualitativo mais seguro. A inclusão dos professores no processo de desenvolvimento e apresentação das palestras de química pode facilitar o acompanhamento de mudanças relativas à crença na autoeficácia dos estudantes.

A crença na autoeficácia é fundamental para a motivação para a aprendizagem em diversos aspectos, como para o aumento do esforço, da perseverança e também resiliência perante dificuldades e fracassos. Os pressupostos da crença na autoeficácia em ambientes escolares geralmente são utilizados de forma diagnóstica. A literatura apresenta estudos sobre a percepção de autoeficácia em diferentes níveis escolares, a 
relação com o desempenho escolar e a influência do professor nesse processo. Neste trabalho, a teoria de Bandura embasou o estudo de um aspecto da motivação a partir de uma intervenção escolar. Os instrumentos de coleta de dados utilizados mostraramse suficientemente adequados para acompanhar o impacto de uma atividade não usual sobre os estudantes. Diversas contribuições de estudos na área de ensino de Ciências, em termos de propostas metodológicas, vem sendo divulgadas como alternativas ao ensino tradicionalmente adotado nas escolas. A Teoria Sócio Cognitiva pode ser considerada como uma fundamentação importante para avaliar essas propostas do ponto de vista motivacional.

Sendo a química pouco prestigiada por sua complexidade e pela forma como muitas vezes é abordada no espaço escolar, atividades de divulgação científica que promovam interação e engajamento dos estudantes, que despertem sua curiosidade e favoreçam seu envolvimento cognitivo são importantes e podem ser exploradas visando promover a crença na autoeficácia. Dessa forma, estudos futuros podem ser desenvolvidos nessas perspectivas assim como também incluindo o professor da Educação Básica nos processos de desenvolvimento das novas estratégias e da avaliação da sua contribuição para o fortalecimento da crença na autoeficácia de seus estudantes.

Diferentemente das pesquisas diagnósticas que predominam nessa área e que utilizam instrumentos quantitativos para levantamento e análise dos dados, neste trabalho optou-se por uma abordagem qualitativa. Para avaliação de uma intervenção que demandou um ano letivo de coleta de dados, instrumentos que possibilitam o aprofundamento do olhar sobre o participante e a exploração do contexto de forma mais ampla mostraram-se mais adequados. Em trabalhos futuros, pode ser estudada a combinação de instrumentos quantitativos e qualitativos, de modo a possibilitar o aumento da amostra de sujeitos de pesquisa e também uma análise que considere toda a complexidade do contexto escolar.

Por fim, reforça-se a importância de estudos longitudinais, especialmente quando envolvem aspectos sócio cognitivos, como a crença na autoeficácia, pois esta pode influenciar o estudante tempos após a ocorrência da intervenção.

\section{Agradecimentos}

As autoras agradecem aos funcionários do Museu da Ciência "Professor Mário Tolentino" e da Biblioteca da Prefeitura do Campus USP de São Carlos o espaço cedido para aplicação das palestras; aos grupos de pesquisa do IQSC pela parceria; às escolas e, especialmente, aos professores pela participação no estudo; ao Programa Institucional de Iniciação ao Ensino (PIBID/CAPES); à Fundação de Amparo à Pesquisa do Estado de São Paulo (FAPESP) - Processo n. 2014/02522-7; ao Conselho Nacional de Desenvolvimento Científico e Tecnológico (CNPq) - Processo n. 457780/2013-4. 


\section{Referências}

Azevedo, G. C. I. (2005). Transferência de tecnologia através de spin-offs: os desafios enfrentados pela UFSCar. (Dissertação de Mestrado em Ciências Exatas e da Terra). Universidade Federal de São Carlos, São Carlos.

Axelsen, M. (2006). Using special events to motivate visitors to attend art galleries. Museum Management and Curatorship, 21(3), 205-221.

Bandura, A. (1994). Self-efficacy. In V. S., Ramachaudran (Ed.), Encyclopedia of human behavior, 4, (pp. 71-81). New York: Academic Press. (Reprinted in H. Friedman (Ed.), Encyclopedia of mental health. San Diego: Academic Press, 1998).

Bandura, A. (2001). Social cognitive theory: An agentic perspective. Annual review of psychology, 52(1), 1-26.

Bandura, A. (2009). Social cognitive theory of mass communications. In J., Bryant, \& M. B., Oliver (Eds). Media Effects: Advances in theory and research, 2nd Ed. (pp. 94-124) Mahwah, NJ: Lawrencec Erlbaum.

Bogdan, R. C., \& Biklen, S. K. (1994). Investigação qualitativa em educação: uma introdução à teoria e aos métodos. Tradução Maria J. Alvarez, Sara B. dos Santos e Telmo M. Baptista. Porto: Porto Editora.

Bryan, R. R., Glynn, S. M., \& Kittleson, J. M. (2011). Motivation, achievement, and advanced placement intent of high school students learning science. Science education, 95(6), 1049-1065.

Bzuneck, J. A., \& Guimarães, S. E. R. (2007). Estilos de professores na promoção da motivação intrínseca: reformulação e validação de instrumento. Psicologia: Teoria e Pesquisa, 23(4), 415-422.

Bzuneck, J. A. (2009). As crenças de auto-eficácia e o seu papel na motivação do estudante. In E., Boruchovitch, \& J. A., Bzuneck (Orgs.), A motivação do estudante: contribuições da psicologia contemporânea. (pp. 116-133). Petrópolis, RJ: Vozes.

Cheung, D. (2009). Developing a Scale to Measure Students' Attitudes toward Chemistry Lessons, International Journal of Science Education, 31(16), 2185-2203.

Cordeiro, M. R., Vaciloto, N. C. N., Virtuoso, L. S., \& Kiill, K. B. (2013). O papel da experimentação para professores de ciências. Enseñanza de las ciencias: revista de investigación y experiencias didácticas [online], Núm. Extra, 818-824.

Demircioglu, G., Aslan, A., \& Yadigaroglu, M. (2014). Exploratory factor analysis study for the scale of high student's attitudes towards chemistry. International Journal on New Trends in Education and Their Implications, 5.

Demo, P. (2007). Escola pública e escola particular: semelhanças de dois imbróglios educacionais. Ensaio: avaliação e políticas públicas em educação, 15(55). 
Dietrich, H., \& Schibeci, R. (2003). Beyond public perceptions of gene technology: community participation in public policy in Australia, Public Understanding of Science. (12), 38-401.

Falcão, A. (2009). Museu como lugar de memória. In: Museu e Escola: educação formal e não-formal. BRASIL: Coleção Salto para o Futuro. Ano XIX. (3).

Fávero, M. L. A. (2006). A Universidade no Brasil: das origens à Reforma Universitária de 1968. Educar em Revista, 28(1), 17-36.

Ferrell, B., \& Barbera, J. (2015). Analysis of students' self-efficacy, interest, and effort beliefs in general chemistry. Chemistry Education Research and Practice, 16(1), 318-337.

Fraser, M. T. D., \& Gondim, S. M. G. (2004). Da fala do outro ao texto negociado: discussões sobre a entrevista na pesquisa qualitativa. Paidéia, 14(28), 139-152.

Friedman, I. A., \& Kass, E. (2001). Teacher self-efficacy: A classroom-organization conceptualization. Teaching and teacher education, 18(6), 675-686.

Gohn, M. G. (2016). Educação não formal nas instituições Sociais. Revista Pedagógica, Chapecó, 18(39), 59-75.

Goya, A., Bzuneck, J. A., \& Guimarães, S. É. R. (2008). Crenças de eficácia de professores e motivação de adolescentes para aprender Física. Psicologia Escolar e Educacional, 12(1), 51-67.

Iaochite, R. T., Costa Filho, R. A., Matos, M. M., \& Sachimbombo, K. M. C. (2016). Autoeficácia no campo educacional: revisão das publicações em periódicos brasileiros. Psicologia Escolar e Educacional, 20(1), 45-54.

Kasseboehmer, A. C., Hartwig, D. R., \& Ferreira, L. H. (2015). Contém química 2: pensar, fazer e aprender pelo método investigativo. 2. ed. São Carlos: Pedro \& João Editores.

Kasseboehmer, A. C., \& Parra, K. N. (2015). Debates sobre a Divulgação Científica da Química no Brasil. In: T. H. B., Corrêa, G. A., Matharan, \& L. F. M., Pérez (Orgs.). O Ensino de Química em Diálogo. (pp. 11-34) 1ed. Curitiba, PR: CRV.

Madjar, N., \& Chohat, R. (2016). Will I succeed in middle school? A longitudinal analysis of self-efficacy in school transitions in relation to goal structures and engagement. Educational Psychology, 1-15.

Marandino, M. (2004). Transposição ou recontextualização? Sobre a produção de saberes na educação em museus deficiencias. Revista Brasileira de Educação, (26), 95-108.

Marandino, M. (2005). Museus de ciências como espaços de educação. Museus: dos gabinetes de curiosidade à museologia moderna. Belo Horizonte: Argumentum, 165176.

Martins, L. C., Navas, A. M., Contier, D., \& Souza, M. P. C. (2013). Que público é esse? Formação de públicos de museus e centros culturais. 1. ed., São Paulo, SP: Percebe. 
Mencl, J., Tay, L., Schwoerer, C. E., \& Drasgow, F. (2012). Evaluating quantitative and qualitative types of change: An analysis of the malleability of general and specific selfefficacy constructs and measures. Journal of Leadership \& Organizational Studies, 19(3), 378-391.

Midgley, C., Feldlaufer, H., \& Eccles, J. (1989). Change in teacher efficacy and student self- and task-related beliefs in mathematics during the transition to junior high school. Journal of Educational Psychology, 81, 247-258.

Parra, K. N., Silva, D. M., \& Kasseboehmer, A. C. (2015). Percepções sobre a universidade pública: o que pensa a população da cidade dos doutores? In: Congreso de la RedPOP. Arte, tecnología y ciencia: nuevas maneras de conocer? Medellín, Colômbia.

Park, H. R., Park, J. W., Kim, C. J., \& Song, J. E. (2016). Development and validation of simulation teaching strategies in an integrated nursing practicum. Collegian.

Pauletti, F. Entraves ao ensino de química: Apontando meios para potencializar este ensino. (2012). Areté, 5(8).

Pereira, M. R. D. S. (2014). O Docente e sua postura pedagógica como aspecto motivador da aprendizagem no ensino de química. Monografia (Curso de Especialização em Fundamentos da Educação). Universidade Federal da Paraíba, PB.

Pintrich, P. R., \& De Groot, E. V. (1990). Motivational and self-regulated learning components of classroom academic performance. Journal of educational psychology, $82(1), 33$.

Salta, K., \& Tzougraki, C. (2004). Attitudes toward chemistry among 11 th grade students in high schools in Greece. Science Education, 88(4), p. 535-547.

Santos, W. L. P. (2011). Popularização do ensino de química para a vida e para a justiça social. ComCiência. (130).

Severo, I. R. M., \& Kasseboehmer, A. C. (2017). Motivação dos alunos: reflexões sobre o perfil motivacional e a percepção dos professores. Química Nova na Escola (Impresso), 39(1), 75-82.

Skaalvik, E. M., \& Skaalvik, S. (2010). Teacher self-efficacy and teacher burnout: A study of relations. Teaching and teacher education, 26(4), 1059-1069.

Studart, D. C. (2000). The perceptions and behaviour of children and their families in child-orientated museum exhibitions. Tese (Doutorado em Estudos Museais), University of London.

Teruya, L. C., Marson, G. A., Rezende, C. M., \& Viana, M. H. (2013). Imagem pública e divulgação da química: desafios e oportunidades. química Nova, 36(10), 1561-1569.

Valente, M. E., Cazelli, S., \& Alves, F. (2005). Museus, ciência e educação: novos desafios. História, Ciências, Saúde - Manguinhos, 12(Suppl.), 183-203. 
Zee, M., \& Koomen, H. M. (2016). Teacher self-efficacy and its effects on classroom processes, student academic adjustment, and teacher well-being: A synthesis of 40 years of research. Review of Educational Research, 86(4), 981-1015.

Kenia Naara Parra

${ }^{0}$ https://orcid.org/0000-0003-1007-5965

Universidade de São Paulo Instituto de Química de São Carlos

São Carlos, Brasil

keniaparra@usp.br

Ana Cláudia Kasseboehmer

${ }^{10}$ https://orcid.org/0000-0002-3140-453X Universidade de São Paulo Instituto de Química de São Carlos

São Carlos, Brasil claudiaka@iqsc.usp.br

Submetido em 05 de Setembro de 2017

Aceito em 18 de Janeiro de 2018

Publicado em 22 de Abril de 2018 